\title{
Influence of Biopreparations on Phytoremediation of Petroleum-Contaminated Soil
}

\author{
Oleksandr Karpenko ${ }^{1}$, Andriy Banya ${ }^{2}$, Volodymyr Baranov ${ }^{3}$, \\ Volodymyr Novikov ${ }^{1}$, Barbara A. Kołwzan ${ }^{4 *}$ \\ 'Department of Biologically-Active Substances, Pharmacy and Biotechnology, Lviv Polytechnic National University \\ ${ }^{2}$ Department of Physical Chemistry of Fossil Fuels InPOCC NAS of Ukraine, Lviv, Ukraine \\ ${ }^{3}$ Department of Biology, I. Franko Lviv National University, Lviv, Ukraine \\ ${ }^{4}$ PZITS Lower Silesian Branch
}

Received: March 22, 2015

Accepted: May 27, 2015

\begin{abstract}
We analyzed the effects of biosurfactants and microbial preparation on the efficacy of phytoremediation of soil contaminated with petroleum $(2,5$, and $8 \%$ ) with the use of field pea (Pisum arvense L.). We also studied their effect on the intensity of lipid peroxidation (LPO) in plants. It has been shown that field peas can be used in the phytoremediation of soils contaminated with crude oil. The best effect of the remediation process was achieved through the use of biosurfactants and a preparation containing petroleum-degrading microorganisms. In the first stage the biodegradation process was stimulated using biopreparation; in the second stage the seeds treated with biosurfactant solutions (rhamnolipid biocomplex or trehalose lipids) were planted on the polluted soil.

As a result, the content of pollution in soil was reduced by $60-65 \%$ after two months. The reduction of lipid peroxidation (malondialdehyde content) as a result of the combined effect of petroleum-degrading microorganisms and biosurfactants on field pea seedlings grown in contaminated soil was observed. The method used provides a preliminary partial degradation of petroleum in soil by microorganisms, while biosurfactants can promote better absorption of nutrients and water, thereby reducing the toxic effects of petroleum and oxidative stress in the plants. The results demonstrate the applicability of this combined approach in the process of remediation of soils contaminated by petroleum.
\end{abstract}

Keywords: soil, phytoremediation, petroleum products, biopreparation, biosurfactant

\section{Introduction}

Environmental pollution by petroleum products a mixture of compounds, primarily hydrocarbons, with different physical, chemical and biological properties - poses a serious ecological problem. Contamination of water and soil with these substances causes significant changes in the environment, adversely affects crop production, and poses a potential danger to human and animal health. Due to the toxic properties of the compounds included in the petrole-

*e-mail: barbara.kolwzan@gmail.com um products, contaminated areas should be treated shortly after contamination using reclamation methods. Biological methods of environment restoration (bioremediation, phytoremediation), that is treatment with microorganisms and plants, are considered to be the most promising and environmentally acceptable methods [1]. Due to the great power of natural detoxification processes, interest in the ecological potential of microorganisms and plants has increased in the last two decades [1-3].

The advantages of phytoremediation technologies include considerably lower cost and ease of implementation, as well as the possibility of transforming the pollutant 
structure as a result of degradation, allowing them to be included in the natural cycle of matter of the biosphere [4-6]. The realization of phytoremediation technologies implies the planting of a contaminated area with one or more specific, previously selected species of plants that have the potential to extract the contaminants from the soil [7-9].

However, low bioavailability of oil hydrocarbons is a major factor limiting their biodegradability. That is why developing methods of increasing plant tolerance to adverse conditions such as soil contamination is an important task. Use of biosurfactants can improve the bioavailability of hydrophobic contaminants such as petroleum hydrocarbons by desorption from soil particles and increase their solubility, and can affect the surface of cells, regulating their transport $[10,11]$. Biosurfactants are not inferior to the synthetic ones by their efficiency and, at the same time, are environmentally friendly. Due to its physico-chemical properties (desorption of hydrophobic substances from the soil, their solubilization, reduction of surface and interfacial tension of solutions) and biological activity, biosurfactants may increase the degree of biodegradation of the contaminants $[12,13]$.

Plants and microorganisms, together or individually, mainly through their powerful oxidative enzyme systems, are able to remediate environments polluted by a wide spectrum of contaminants. An important role in plant adaptation toward unfavorable environmental factors is played by biochemical protection systems. These include antioxidant systems along with enzymatic ones. Antioxidant enzymes are involved in the neutralization of reactive oxygen species (ROS), whose accumulation in plant cells initiates a process of oxidative degradation of membrane structures with the formation of malondialdehyde (MDA) a product of lipid peroxidation (LPO) [14]. However, ROS and LPO products can act as signaling molecules that are involved in the activation of protection systems under stress conditions [15]. In this regard, the topical task is the development of complex technological approaches to soil remediation from complex contamination using effective stimulants of phytoremediation and microbial remediation.

Respectively, the main aim of the presented research is the determination of oil degradation efficiency in soil using phytoremediation techniques under the complex influence of oil-degrading microorganisms and biosurfactants, as well as the degree of LPO in field pea seedlings grown on contaminated soil.

\section{Experimental Procedures}

\section{Materials}

Sod-podzol soil with pH 6.2 was used in our study. The crude oil for the experiments was obtained from the Boryslavnaftogaz Oil Gas Producing Department of OJSC Ukrnafta. The oil has the following parameters: specific gravity of $0.87 \mathrm{~g} / \mathrm{cm}^{3}$, freezing temperature is $130^{\circ} \mathrm{C}$, alkanes content is $5.3 \%$, sulfur content is $0.87 \%$, resin content is
$17 \%$, and asphaltenes content is $1.05 \%$. The soil was spiked with oil to achieve final concentrations of 2,5 , and $8 \% \mathrm{w}$. Sod-podzol soil without oil addition of crude oil was used as control.

\section{Production of Microbial Preparations for Vegetation and Field Experiments}

Preparations of oil-degrading microorganisms (isolated from oil-contaminated soils from sites of western Ukraine) were cultivated on liquid Goodwin medium with $2 \%$ of liquid paraffin as a carbon source (during $3-5$ days, $28-30^{\circ} \mathrm{C}$ ) [16].

Microbial synthesis of biosurfactants [17-19] was conducted using the strains-producers of the genera Pseudomonas and Gordonia on optimized liquid medium with glycerol, mannitol, hexadecane, and plant oil industry wastes $(20 \mathrm{~g} / \mathrm{l})$. Rhamnolipid biocomplex were isolated from cultural broth via acid precipitation $(10 \% \mathrm{HCl}$ to $\mathrm{pH}$ 3 ). Trehalose lipids were isolated via extraction with Folch mixture (chloroform-isopropanol 2:1) from cell mass. The lipids were analyzed via thin layer chromatography and HPLC. The content of rhamnolipids was determined using orcinol method and trehalose lipids using the antron method.

\section{Vegetation Experiments [20]}

The experiments were carried out in vessels $(500 \mathrm{ml})$ with $400 \mathrm{~g}$ of soil in each. Twenty-five seeds were sown in each vessel. The seeds were soaked in RL and TL solutions (concentrations 0.01 and $0.05 \mathrm{~g} / \mathrm{L}$, respectively) for $3 \mathrm{~h}$ and sown in soil artificially contaminated with oil.

In experiments on combined remediation, the contaminated soil was preliminarily treated with a preparation of oildegrading microorganisms in quantity $25 \mathrm{ml}$ (CFU $5 \times 10^{\circ}$ ) per $0.5 \mathrm{~kg}$ of soil. After two weeks the plants were planted and grown in laboratory conditions under daylight illumination, the length and the weight of seedlings, as well as the LPO index, were determined in triplicate after 28 days. Residual oil concentration, counts of microorganisms, and dehydrogenase activity were determined in triplicate after 90 days.

The scheme of research was the following:

1. Control $(\mathrm{C})$ - seeds soaked in distilled water and planted in oil-contaminated soil.

2. D - seeds soaked in distilled water and planted in oilcontaminated soil with the addition of hydrocarbondegrading microbial preparation.

3. RL - seeds soaked in a solution of rhamnolipid biocomplex and planted in oil-contaminated soil.

4. $\mathrm{RL}+\mathrm{D}-$ seeds soaked in a solution of rhamnolipid biocomplex and planted in oil-contaminated soil with the addition of hydrocarbon-degrading microbial preparation.

5. TL - seeds soaked in the solution of trehalose lipids and planted in oil-contaminated soil.

6. TL $+\mathrm{D}-$ seeds soaked in a trehalose lipid solution and planted in oil-contaminated soil with the addition of hydrocarbon-degrading microbial preparation. 
Plants were grown in laboratory conditions at +18 $+20^{\circ} \mathrm{C}$ under white fluorescent daylight lamps (light intensity 4,500 lux) at daylight length of $12 \mathrm{~h}$ for 14 days, followed by the analysis of morphometric and biochemical indices. The experiment was carried out in four replicates.

\section{Determination of Residual Petroleum Concentration in Soil}

Analysis of the residual petroleum was carried out using the gravimetric method [21]. Soil samples after bioremediation were extracted with tetrachloromethane in Soxhlet extractor, the extract was purified of polar compounds on the chromatographic aluminum oxide column, solvent was evaporated, and the oil concentration was determined gravimetrically.

\section{Intensity of Lipid Peroxidation (LPO)}

The method is based on the interaction of malondialdehyde with 2-thiobarbituric acid. As a result the colored product with maximum absorption at a wavelength of $532 \mathrm{~nm}$ was formed [14].

\section{Determination of Dehydrogenase Activity of Soil}

The dehydrogenase activity of soil was determined using the colorimetric method with triphenyltetrazolium chloride (TTC) [22]. This soil sample was incubated with TTF for $24 \mathrm{~h}$ and then extracted with acetone, and extracts were analyzed colorimetrically at $\lambda=485 \mathrm{~nm}$ (Shimadzu UVmini-1240, Shimadzu Corp., Japan). The dehydrogenase activity was determined by the calibration graph by the concentration of 1,3,5-triphenylformazan (TPF), which is formed in the reaction. Total dehydrogenase activity measured in mg TFF to $1 \mathrm{~g}$ soil in 24 hours.

\section{Counts of Soil Microorganisms}

The method of serial dilutions [23] was used for the analysis of soil microorganisms. $1 \mathrm{~mm}$ of each soil extract suspension was introduced to a Petri dish, incubated at $30^{\circ} \mathrm{C}$ for five days, and the number of colonies was counted taking the dilution into account. The study was performed in five replicates.

The experimental data were statistically processed for the determination of the deviation from the mean using Statist and Excel.

\section{Results and Discussion}

An important task in the development of the effective phytoremediation technologies is finding the approach to the increase of plant tolerance to adverse conditions, such as soil contamination. To enhance the bioavailability of organic pollutants in soil, some synthetic amendments (Tween 80, citric and oxalic acids, biochar, and methylated $\alpha$-cyclodextrins) were successfully applied in assisting phy- toremediation of organically polluted soils [24-26]. The literature presents more information on the use of biosurfactants in phytoremediation of soils contaminated with heavy metals. For instance, biosurfactant-producing Bacillus (sp. J119 strain) was investigated for its capability to promote plant growth and cadmium uptake of rape, maize, sudangrass, and tomato in soil contaminated with different levels of Cd [10].

For this purpose the influence of soil treatment with microbial preparation $\mathrm{D}$ as well as pre-sowing treatment of seeds with biosurfactants on the growth parameters of field pea (Pisum arvense L.) when growing on petroleum-containing soil (2, 5 and $8 \%$ ) was studied. The plants were planted two weeks after the soil treatment with microbial preparation. The results are presented in Figs. 1-3.

It has been revealed that in soils with different oil content $(2,5$ and $8 \%)$, morphometric characteristics of plants after the pre-sowing treatment with the biosurfactant solutions and the use of oil-degrading microorganisms was significantly greater than in control plants. Thus shoot and root lengths increased $15 \%$ and $48 \%$, respectively (soil contamination $2 \% \mathrm{w}$.) and $22 \%$ and $12 \%$ (contamination $5 \% \mathrm{w}$.) when adding the microbial preparation (D) into the contaminated soil without biosurfactants. An insignificant

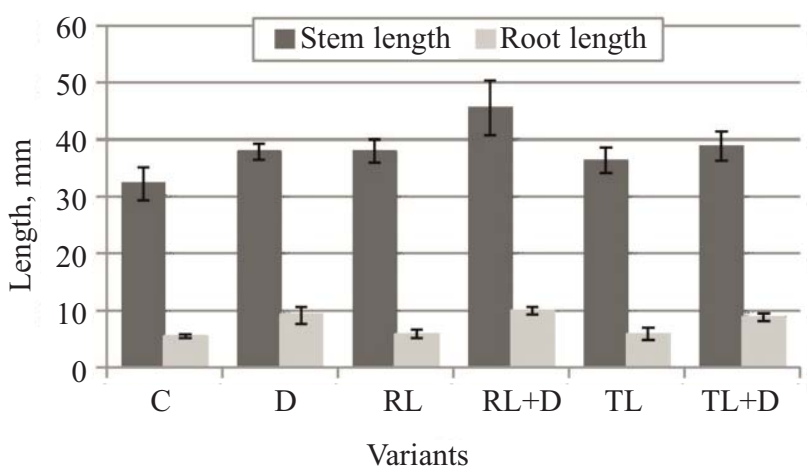

Fig. 1. Influence of microbial preparation $\mathrm{D}$ and biosurfactants on the lengths of roots and stems of field pea seedlings when grown on oil-contaminated soil $(2 \%$ w.). C - control, D microbial preparation, RL - rhamnolipid biocomplex, TL - trehalose lipids.

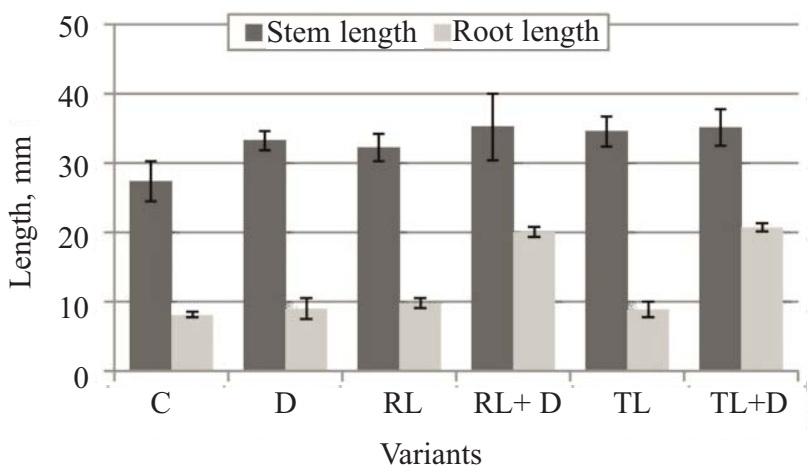

Fig. 2. The influence of microbial preparation $\mathrm{D}$ and biosurfactants on the lengths of roots and stems of field pea seedlings when grown on oil-contaminated soil (5\% w.). C - control, D microbial preparation, RL - rhamnolipid biocomplex, TL - trehalose lipids. 


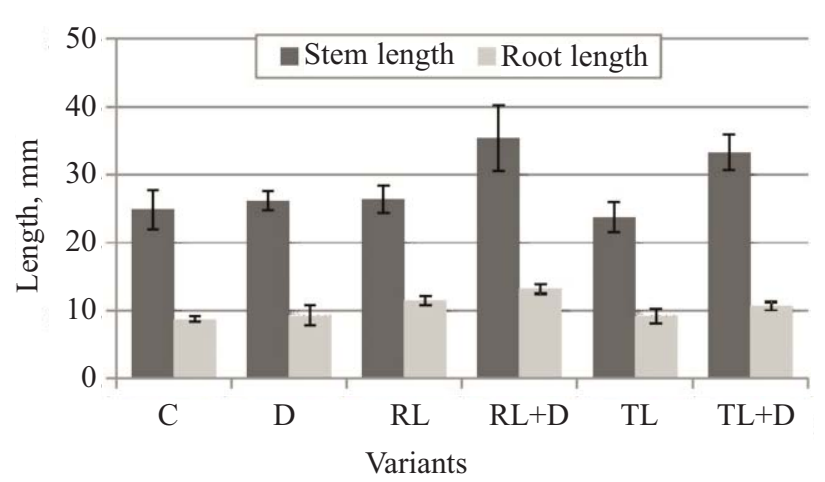

Fig. 3. Influence of microbial preparation D and biosurfactants on the lengths of roots and stems of field pea seedlings when grown on oil-contaminated soil $(8 \%$ w.). C - control, D microbial preparation, RL - rhamnolipid biocomplex, TL - trehalose lipids.

increase in growth performance (compared to control) was observed in the option with the pre-sowing treatment of seeds of field pea with RL and TL solutions without introducing microbial preparation - for RL the shoot and root lengths increased $18 \%$ and $14 \%$, respectively (soil contamination $2 \% \mathrm{w}$.), but only on $4 \%$ and $33 \%$, respectively, while growing on soil with $8 \% \mathrm{w}$. crude oil content.

The best plant growth parameters were observed in the combined use of microbial preparation and biosurfactant. However, the combined effects of the biosurfactant and microbial preparation showed the best growth parameters: shoot and root length was $43 \%$ and $67 \%$ greater under the influence of RL + D (2\% w. of crude oil), $29 \%$ and $60 \%$ (D + RL, TL + D, $2 \% \mathrm{w}$. of crude oil), and on $40 \%$ and $55 \%$ ( $8 \% \mathrm{~W}$. of crude oil) if compared with respective controls. The stimulating effect was observed for all three concentrations of oil in the soil.

The obtained results are consistent with several reports from literature on the joint application of various biological preparations for remediation of soils. Thus, in [27] the positive results of the remediation of soil from polyaromatic hydrocarbons using hydrocarbon-degrading microorganisms - alfalfa with the addition of rhamnolipids - are presented.

These results suggest the possibility of using oildegrading microorganisms and biosurfactants for the increase of plant tolerance to adverse conditions, such as petroleum-contaminated soils.

It is known from the literature that activation of lipid peroxidation (LPO) in plants when growing in adverse environmental conditions is accompanied by various modifications of the metabolism of plants. These processes in turn are caused by both direct oxidation of membrane lipids and the accumulation of lipid peroxidation products and their interaction with cellular macromolecules [28]. Therefore, the LPO intensity is an important indicator of the degree of influence of various stress factors on the organism, which characterizes its functional state and nonspecific adaptive capacity. Study of the effect of abiotic stress factors on the content of malondialdehyde as an indicator of LPO activity provides the possibility to establish a relationship between the stress factor type, its dose, and LPO intensity. We have identified an LPO indicator for plants when growing on oil-contaminated soil and the influence of biosurfactants and microbial preparations on these parameters (Figs. 4-6).

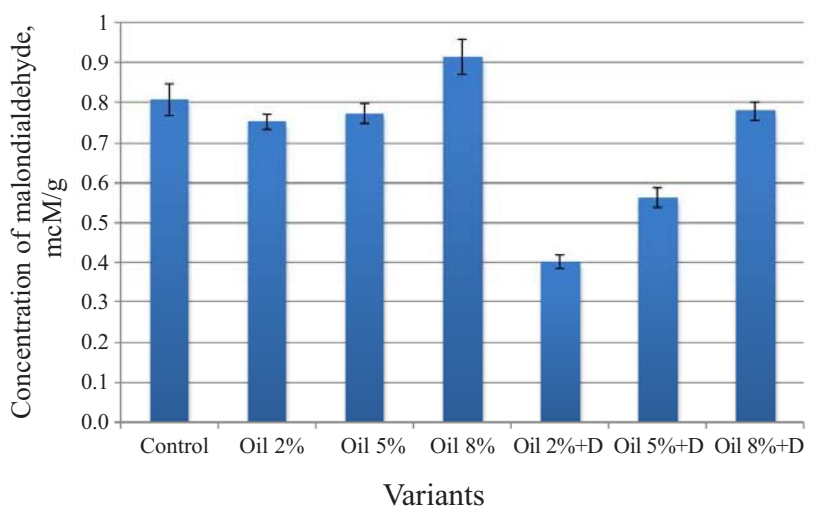

Fig. 4. Effect of oil-degrading microorganisms on the content of malondialdehyde in 21-day field pea seedlings when grown in soil with different oil concentrations (control variant). Reliability of the results of the experiment $(\mathrm{p}<0.05)$.

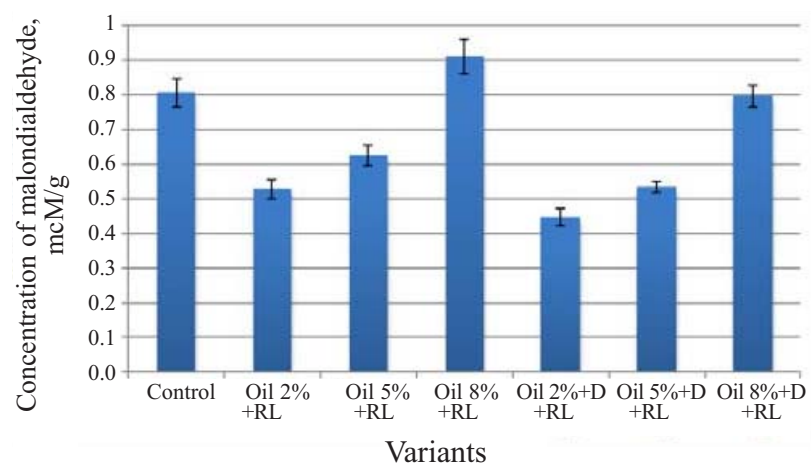

Fig. 5. Effect of rhamnolipid biocomplex on the content of malondialdehyde in 21-day field pea seedlings when grown in soil with different oil concentrations with the addition of oildegrading microorganisms. Reliability of the results of the experiment $(\mathrm{p}<0.05)$.

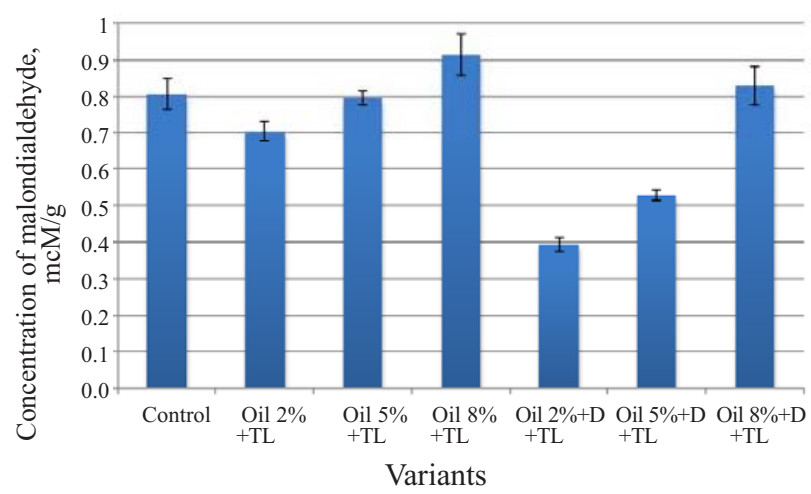

Fig. 6. Effect of trehalose lipids on the content of malondialdehyde in 21-day field pea seedlings when grown in soil with different oil concentrations with the addition of oil-degrading microorganisms. Reliability of the results of the experiment $(\mathrm{p}<0.05)$. 
Thus it was determined that the introduction of the microbial preparation into the soil contributed to the reduction of the content of malondialdehyde in the LPO process, in particular in options with crude oil content in soil of $2 \%$ and $5 \%$ to $43 \%$ and $24 \%$, respectively. This fact testifies to the reduction of oxidative stress under the influence of the microbial preparation when growing in adverse conditions. It can be seen from the obtained data that the introduction of oil-degrading microorganisms resulted in a rather significant reduction of malondialdehyde content in the field pea in soil with the entire concentration of oil pollution $(2,5$, and $8 \%$ ) compared with the control (Fig. 2), and that in our opinion the most interesting in quite toxic pollution by $8 \%$.

The presence of oil-degrading microorganisms in all variants decreased the LPO activity if compared to its activity in oil-contaminated soil. LPO activity slightly decreased in soil with $2 \%$ oil pollution and increased with increasing

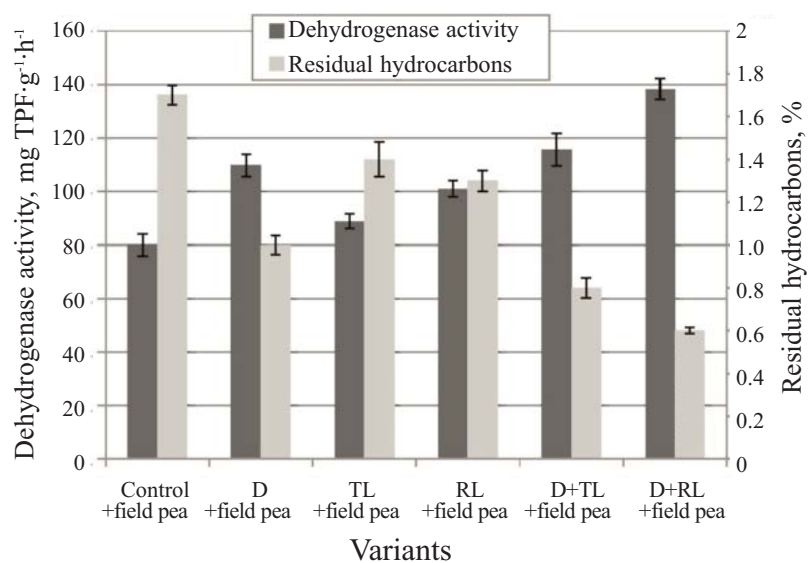

Fig. 7. Complex remediation of oil-contaminated soil $(2 \%$ w. $)$ using microbial preparation $\mathrm{D}$, field pea, and biosurfactants (pre-sowing treatment of seeds); soil dehydrogenase activity and concentration of residual hydrocarbons: D - microbial preparation (pre-treatment), RL - rhamnolipid biocomplex, TL - trehalose lipids.

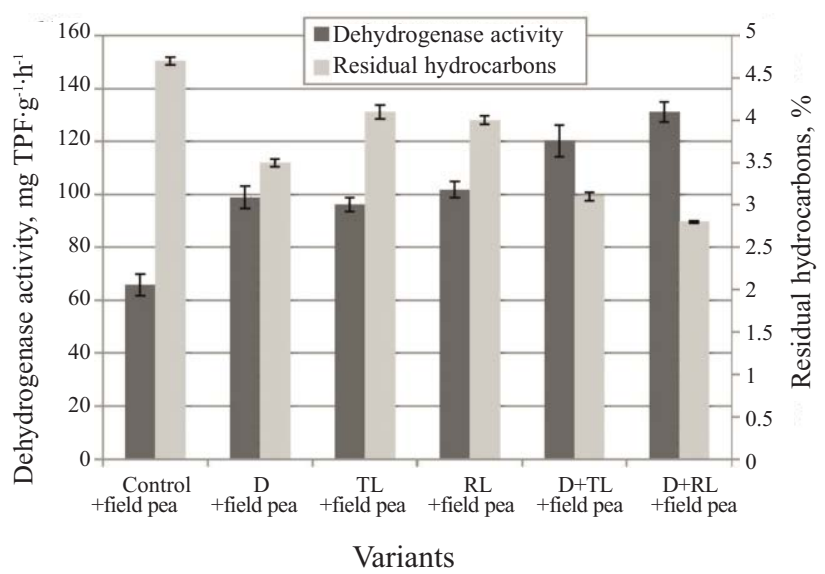

Fig. 8. Complex remediation of oil-contaminated soil $(5 \%$ w. $)$ using microbial preparation $\mathrm{D}$, field pea, and biosurfactants (pre-sowing treatment of seeds) - soil dehydrogenase activity and concentration of residual hydrocarbons: D - microbial preparation (pre-treatment), RL - rhamnolipid biocomplex, TL - trehalose lipids.
Table 1. Complex remediation of oil-contaminated soil using microbial preparation D, field pea, and biosurfactants (presowing treatment of seeds) - soil microbial counts.

\begin{tabular}{|c|c|c|}
\hline $\begin{array}{l}\text { Initial oil } \\
\text { content \% }\end{array}$ & Variants & $\begin{array}{c}\text { Soil microbial counts, } \\
\text { CFU/g }\end{array}$ \\
\hline \multirow{6}{*}{2.0} & Control + field pea & $61 \times 10^{8}$ \\
\hline & $\mathrm{D}+$ field pea & $47 \times 10^{9}$ \\
\hline & $\mathrm{TL}+$ field pea & $10 \times 10^{7}$ \\
\hline & $\mathrm{RL}+$ field pea & $78 \times 10^{8}$ \\
\hline & $\mathrm{D}+\mathrm{TL}+$ field pea & $40 \times 10^{9}$ \\
\hline & $\mathrm{D}+\mathrm{RL}+$ field pea & $25 \times 10^{9}$ \\
\hline \multirow{6}{*}{5.0} & Control + field pea & $87 \times 10^{7}$ \\
\hline & $\mathrm{D}+$ field pea & $48 \times 10^{8}$ \\
\hline & $\mathrm{TL}+$ field pea & $16 \times 10^{8}$ \\
\hline & $\mathrm{RL}+$ field pea & $31 \times 10^{8}$ \\
\hline & $\mathrm{D}+\mathrm{TL}+$ field pea & $28 \times 10^{8}$ \\
\hline & $\mathrm{D}+\mathrm{RL}+$ field pea & $36 \times 10^{8}$ \\
\hline \multirow{6}{*}{8.0} & Control + field pea & $18 \times 10^{6}$ \\
\hline & $\mathrm{D}+$ field pea & $21 \times 10^{7}$ \\
\hline & $\mathrm{TL}+$ field pea & $11 \times 10^{7}$ \\
\hline & RL + field pea & $15 \times 10^{7}$ \\
\hline & $\mathrm{D}+\mathrm{TL}+$ field pea & $82 \times 10^{7}$ \\
\hline & $\mathrm{D}+\mathrm{RL}+$ field pea & $93 \times 10^{7}$ \\
\hline
\end{tabular}

D - microbial preparation (pre-treatment), RL - rhamnolipid biocomplex, TL - trehalose lipids.

concentrations of oil. When applying oil-degrading microorganisms, the LPO activity decreased if compared to the effect of oil alone (Fig. 2-4).

The reduction of malondialdehyde content was also observed in options with pre-sowing treatment of seeds with biosurfactant solutions (RL and TL). The greatest adaptogenic (anti-stress) effect was achieved in an option with a complex approach of introducing the microbial preparation into the soil followed by sowing of biosurfactant-treated seeds. In the case of RL treatment the content of malondialdehyde was reduced on $42 \%$ ( $2 \% \mathrm{w}$. of oil), $32 \%(5 \% \mathrm{w}$. of oil), and $12 \%(8 \% \mathrm{w}$. of oil) if compared with control. In applying the TL we observed similar trends, but at pollution the effect was $8 \%$ lower. Similar trends were observed when applying TL, but in the option with $8 \% \mathrm{w}$. of contamination the effect was smaller.

When soaking the field pea seeds in biosurfactant solutions (rhamnolipid biocomplex and trehalose lipids) before sowing in oil-contaminated soil, and soil with the addition of oil-degrading microorganisms (Fig. 2-4) the more positive effect of biocomplex in soil with 2 and $5 \%$ pollution was observed (the content of MDA decreased), whereas $8 \%$ oil pollution caused the increase of MDA content higher than in the control. When oil-degrading microorganisms 
and rhamnolipid biocomplex or trehalose lipids were applied together the reduction of LPO activity was observed at all concentrations of oil pollution $-2,5$, and $8 \%$ if compared with the variants without an introduction of oil-degrading microorganisms. Since plants use an antioxidant system for protection against the harmful effects of reactive oxygen species [29], the reduction of malondialdehyde - a product of lipid peroxidation - is an important index of the reduction of the stress load for field peas grown in contaminated soil under the influence of biosurfactants and microbial preparations.

The efficiency of combined phytoremediation of petroleum-contaminated soil ( 2 and $5 \%$ w.) using field pea, microbial preparation $\mathrm{D}$, and biosurfactants was estimated by the parameters of residual concentration of hydrocarbons, dehydrogenase activity, and soil microbial counts (Figs. 7 and 8, Table 1).

It was shown that the best remediation effect was observed in a variant with an application of microbial preparation $\mathrm{D}$ and following the sowing of field pea seeds pre-treated with rhamnolipid biocomplex solutions. The degree of oil degradation made $50-75 \%$ in 1.5 months. The data are consistent with dehydrogenase activity and microbial counts in soil.

Use of the preparation of oil-degrading microorganisms - especially in combination with biosurfactants - increases the counts of soil microorganisms quite significantly, by 23 times if compared with the control, which in turn leads to the degradation of contaminants and reduction of the activity of oxidative processes in plant seedlings that can be seen by the reduction of MDA content. In our opinion, the biological preparations not only initiate microflora, but also influence the destruction of oil hydrocarbons, thereby optimizing the rhizobial processes and creating favorable conditions for plants [30].

Thus, the efficiency of the combined approach to phytoremediation of contaminated soils $(2,5$, and $8 \%$ ) was shown: the application of microbial preparation in the first and second stages of the cultivation of field pea in the contaminated soil. Biosurfactants were used to stimulate the growth and development of plants. After growing, the plants can be ploughed into the soil that is used as green manure, which increases organic matter.

\section{Conclusions}

The results of the investigation have shown that the complex application of field pea, preparation of oil-degrading microorganisms, and biosurfactants has considerable practical importance and is an effective method of remediation of oil-contaminated soil. This method can be recommended for the restoration of polluted territories.

\section{References}

1. STROUD J, PATON G., SEMPLE K. Microbe-aliphatic hydrocarbon interactions in soil: implications for biodegradation and bioremediation. J. App. Microbiol. 102, 1239, 2007.
2. TSAO D. Phytoremediation. Advances in Biochemical Engineering and Biotechnology. Berlin-Heidelberg-New York: Springer, 2003.

3. FUTUGHE A. Phytoremediation: A case study. J. Inst. Environ. Sci. 21, (3), 50, 2012.

4. KVESITADZE G. KHATISASHVILI G., SADUNISHVILI T., RAMSDEN J.J. Biochemical Mechanisms of Detoxification in Higher Plants: Basis of Phytoremediation. Berlin, Heidelberg: Springer, 2006.

5. MURATOVA A., TURKOVSKAYA O., HÜBNER T., KUSCHK P. Studies of the Efficacy of Alfalfa and Reed in the Phytoremediation of Hydrocarbon-Polluted Soil. Appl. Biochem. Micro+ 39, 599, 2003.

6. SHAHSAVARI E., ADETUTU E.M., ANDERSON P.A., BALL A.S. Necrophytoremediation of phenanthrene and pyrene in contaminated soil. J. Environ. Manage. 122, 105, 2013.

7. GERHARDT K., HUANG X., GLICK, B. GREENBERG B. Phytoremediation and rhizoremediation of organic soil contaminants: Potential and challenges. Plant Sci. 176, 20, 2009.

8. INZE D., VAN MONTAGU M. Oxidative Stress in Plants. London: Taylor \& Francis, 2002.

9. AHEMAD M., Enhancing phytoremediation of chromiumstressed soils through plant-growth-promoting bacteria. Journal of Genetic Engineering and Biotechnology. Available online, 2015 [In Press].

10. PACWA-PŁOCINICZAK M., PŁAZA G.A., PIOTROWSKA-SEGET Z., CAMEOTRA S.S. Environmental Applications of Biosurfactants: Recent Advances. Int. J. Mol. Sci. 12, (1), 633, 2011.

11. DE CÁSSIA F. S. SILVA R., ALMEIDA D., RUFINO R.D., LUNA J.M., SANTOS V.A., SARUBBO L.A. Applications of Biosurfactants in the Petroleum Industry and the Remediation of Oil Spills. Int. J. Mol. Sci. 15, (7), 12523, 2014.

12. MULLIGAN C. Recent advances in the environmental applications of biosurfactants. Curr. Opin. Colloid In. 14, (5), 372, 2009.

13. DEKA M., DAS K. Effect of biosurfactant from two strains of Pseudomonas on germinating seedlings of Cicer arietinum L. and Phaseolus mungo Roxb. African Journal of Biotechnology, 23, (8), 6621, 2009.

14. BAGNYUKOVA T., LUSHCHAK O., STOREY K., LUSHCHAK K. Oxidative stress and antioxidant defense responses by goldfish tissues to acute change of temperature from 3 to $23^{\circ} \mathrm{C}$. J. Thermal Biol., 32, 227, 2007.

15. LAI C.C., HUANG Y.C., WEI Y.H., CHANG J.S. Biosurfactant-enhanced removal of total petroleum hydrocarbons from contaminated soil. J. Hazard Mater. 167, (1-3), 609, 2009.

16. VILDANOVA-MARTSYSHYN R., POKYNBRODA T., KARPENKO A. Screening of hydrocarbon-degrading microorganisms of from petroleum contaminated objects of Western Ukraine. Bulletin of National University "Lviv Polytechnic," Chemistry, Technology substances and their applications 609, 117, 2008.

17. KARPENKO O., PRYSTAY M., DATSKO B., GAFIJCHUK G., NOGYNA T. Optimization of biosynthesis of surfactants and exopolysaccharides by strain Gordonia rubripertincta UKM AC-122 by mathematical methods. Biotechnology 5, (4), 39, 2011.

18. KARPENKO E., POKINBRODA T., MAKITRA R., PALCHIKOVA E. Optimal Methods of Isolation of Biogenic Ramnolipid Surfactants. Zhurnal Obshchei Khimii. 79, (12), 2637, 2009. 
19. KARPENKO O., PRYSTAY M., MAKYTRA R. PALCHYKOVA O. Optimization for isolation of surfaceactive compounds synthesized by bacteria of the genus Rhodococcus. Scientific Papers Of DNTU, Chemistry \& Chemical Technology. 17, (187), 124, 2011.

20. DSTU 4138-2002. Seeds of agricultural crops. Methodological determination of quality. 01/01/2004. Kyiv. State Standard of Ukraine. 173, 2003.

21. RD 52.18.647-2003. Methodical guidelines. Determination of the mass fraction of oil products in the soil. The method of measurement by gravimetric method.

22. CASIDA L., KLEIN D., SANTORO T. Soil dehydrogenase activity. Soil Sci. 98, 319, 1964.

23. SEGI J. Methods of soil microbiology. Moscow: Kolos, pp. 107-109, 1983.

24. BEESLEY L., MORENO-JIMÉNEZ E., GOMEZ-EYLES $\mathrm{J}$. Effects of biochar and greenwaste compost amendments on mobility, bioavailability and toxicity of inorganic and organic contaminants in a multi-element polluted soil. Environ. Pollut. 158, 2282, 2010.
25. MITTON F., GONZALEZ M., PEÑAA., MIGLIORANZA K.S. Effects of amendments on soil availability and phytoremediation potential of aged p,p'-DDT, p,p'-DDE and p,p'-DDD residues by willow plants (Salix sp.). J. Hazard. Mater. 62, (8), 203, 2012.

26. HAKEEM K., SABIR M., OZTURK M., MERMUT A. Soil Remediation and Plants: Prospects and Challenges. Elsevier: Amsterdam, 2014.

27. JING ZHANG J., RUI Y., XIANGUI L., WEIWEI L., RUIRUI C. Interactive effect of biosurfactants and microorganisms to enhance phytoremediation for removal of aged polycyclic aromatic hydrocarbons from contaminated soils. J. Health. Sci., 56, (3), 257, 2010.

28. MITTLER R. Oxidative stress, antioxidants and stress tolerance. Trends Plant. Sci. 7, (9), 405, 2002.

29. KOLUPAEV J., KARPETS J. Active forms of oxygen in the adaptation of plants to stress temperatures. Physiol. Biochem. Cult. Plants. 41, (2), 95. 2009.

30. D'AES J., DE MAEYER K., PAUWELYN D. Biosurfactants in plant - Pseudomonas interactions and their importance to biocontrol. Environ. Microbiol. Reports. 2, (3), 359, 2010. 
